\title{
Erratum to: Thrombotic events in MYH9 gene-related autosomal macrothrombocytopenias (old May-Hegglin, Sebastian, Fechtner and Epstein syndromes)
}

Antonio Girolami · Silvia Vettore $\cdot$

Emanuela Bonamigo $\cdot$ Fabrizio Fabris

Published online: 14 June 2012

(C) Springer Science+Business Media, LLC 2012

Erratum to: J Thromb Thrombolysis (2011) 32:474-477 DOI 10.1007/s11239-011-0623-4

Unfortunately, the first names and surnames of the authors were interchanged in the original publication of the article.
The correct version should be: "Antonio Girolami, Silvia Vettore, Emanuela Bonamigo, Fabrizio Fabris.”

The online version of the original article can be found under doi:10.1007/s11239-011-0623-4.

A. Girolami $(\bowtie) \cdot S$. Vettore $\cdot$ E. Bonamigo $\cdot$ F. Fabris Department of Medical and Surgical Sciences, University of Padua Medical School, Via Ospedale 105, Padua 35128, Italy e-mail: antonio.girolami@unipd.it 